\title{
PENGARUH PH, WAKTU, NISBAH VOLUME ORGANIK DAN AQUEOUS (O/A) TERHADAP PROSES PEMISAHAN KOBALT DARI SLAG NICKEL PIG IRON (NPI)
}

\section{THE EFFECT OF PH, TIME, VOLUME ORGANIC/AQUEOUS TOWARDS SEPARATION OF COBALT FROM SLAG OF NICKEL PIG IRON}

\author{
Ulin Herlina ${ }^{1}$, Sudibyo ${ }^{1}$, E. Prasetyo ${ }^{1}$, Donny Lesmana ${ }^{2}$, dan Syafira Eka Gestya ${ }^{2}$ \\ ${ }^{1}$ Balai Penelitian Teknologi Mineral - LIPI \\ Jl. Ir. Sutami Km 15 Tanjung Bintang, Lampung Selatan, Indonesia \\ ${ }^{2}$ Fakultas Teknik, Jurusan Teknik Kimia, Universitas Lampung, Indonesia \\ 1,* E-mail: sudibyo@lipi.go.id \\ Diterima : 16-6-21 Direvisi : 1-12-21 Disetujui : 27-12-21
}

\begin{abstract}
ABSTRAK
Nickel Pig Iron (NPI) merupakan ferronikel kualitas rendah yang mana digunakan sebagai alternatif bahan baku untuk mengembangkan pembuatan baja tahan karat. Proses pembuatan NPI menggunakan metode pirometalurgi juga menghasilkan slag yang masih mengandung Kobalt. Pada penelitian ini, proses pemisahan Kobalt dari slag NPI ini menggunakan metode solvent extraction (ekstraksi pelarut). Slag NPI yang telah disamakan ukurannya kemudian dileaching dengan menggunakan asam asetat. Larutan leaching kemudian diatur pH-nya dengan menggunakan $\mathrm{NaOH}$, kemudian dilakukan ektraksi cair-cair tahap pertama dengan Versatic Acid dan kerosene. Extraksi tahap pertama bertujuan untuk mengambil nikel dan kobalt dari larutan leaching. Parameter yang digunakan dalam penelitian ini adalah waktu operasi, nisbah volume $(\mathrm{O} / \mathrm{A})$ dan juga $\mathrm{pH}$ larutan pada ektraksi cair-cair tahap pertama. Parameter tersebut dipelajari dan dioptimasi dengan menggunakan rancangan ekperimen Taguchi. Hasil optimum dari extraksi tahap pertama ini kemudian digunakan pada extraksi tahap Extraksi tahap kedua dengan Cyanex 272 dan kerosene. Extraksi tahap kedua bertujuan untuk mengambil cobalt dari campuran nikel dan cobalt. Hasil analisis Taguchi menunjukkan bahwa kondisi optimum pada proses ekstraksi pelarut menggunakan versatic acid ialah pada waktu 20 menit, pH 6 dan nisbah volume larutan organik / aqueous (O/A) sebesar 0,75.
\end{abstract}

Kata kunci: Cyanex 272, ekstraksi pelarut, pemisahan Cobalt, slag Nickel pig iron, versatic acid

\section{ABSTRACT}

Nickel Pig Iron (NPI) is a low-grade ferronickel used as a raw material for producing stainless steel. To produce NPI using pyrometallurgy method also produce slag which content cobalt. In this research, the process to cobalt separation from NPI slag using solvent extraction method. The powder of NPI Slag was leached using acetic acid. The $\mathrm{pH}$ of leaching solutions was adjusted using $\mathrm{NaOH}$, the first stage of solvent extraction was conducted using versatic acid and kerosene. First stage extraction was conducted due to separate cobalt and nickel from leaching solutions. The parameters were used in this research namely were operating time, volume ratio $(O / A)$, and the solution's $p H$ of aqueous solution in the first stage extraction. Those parameters were studied and optimized using the design experiment of Taguchi. The optimum conditions from first stage extraction are then used in second stage extraction which uses Cyanex 272 and kerosene. The second stage extraction was conducted to separate cobalt from nickel solution. The Taguchi analysis result shows that the optimum condition of first stage extraction was at is at 20 minutes, $p H 6$, and a volume ratio $(O / A)$ of 0.75 .

Keywords: slag of Nickel pig iron, cobalt separation, Cyanex 272, versatic acid, solvent extraction 


\section{PENDAHULUAN}

Obalt adalah suatu unsur kimia dalam tabel periodik yang memiliki lambang Co dengan nomor atom 27 (De-qing et al., 2012). Elemen ini biasanya hanya ditemukan dalam bentuk campuran di alam dalam bijih nikel laterit. Laterit diolah dengan blast furnace akan menghasilkan slag dari pembuatan Nickel Pig Iron (NPI) dimana slag masih mengandung kobalt dikarenakan suhu pada blast furnace yang dibawah titik lebur kobalt. Pada slag NPI ini masih banyak terdapat logam lain yang masih bercampur dengan kobalt sehingga perlu dilakukannya proses solvent extraction agar dapat memisahkan logam lainnya dari kobalt (Sole, 2008). Nikel dan kobalt menempati tempat yang dekat dalam seri logam transisi dalam tabel periodik yang menghasilkan sifat kimia pada fasa aqueous yang terlalu mirip. Ekstraksi pelarut juga memiliki tingkat pemisahan dengan yield yang tinggi dan kemurnian logam yang terpisah juga tinggi (Du Preez and Preston, 2004; Park and Mohapatra, 2006; Sole, 2008).

Pada Penelitian ini, slag NPI yang banyak tidak dimanfaatkan akan diolah menggunakan proses hidrometalurgi untuk mendapatkan logam cobalt. Proses hidrometalurgi yang digunakan adalah solvent extraction dengan menggunakan pelarut organik yang murah yaitu kerosene (minyak tanah). Proses ini dimulai dari proses leaching (pelindian) dengan asam asetat. Penggunaan asam asetat dalam proses pelindian memiliki keuntungan, yaitu tidak berbahaya dan ramah lingkungan (Astuti et al., 2016). Hasil larutan pelindian tersebut diatur $\mathrm{pH}$-nya dengan $\mathrm{NaOH}$ lalu dilanjutkan dengan ekstraksi tahap pertama dengan menggunakan solven Versatic Acid yang diencerkan dengan kerosene (Sole, 2008; Sudibyo et al., 2018). Proses ekstraksi tahap pertama bertujuan untuk mengambil logam nikel dan cobalt dalam larutan hasil leaching. Pada ekstraksi tahap kedua dengan menggunakan solven Cyanex 272 yang diencerkan dengan pelarut organic seperti kerosene (minyak tanah) (Nikam and Mohite, 2012; Sudibyo et al., 2018).

Pada penelitian ini menggunakan metode Taguchi untuk menentukan kondisi optimum dan mempelajari parameter parameter yang berpengaruh pada proses ekstraksi pelarut (Amin et al., 2019; Sudibyo et al., 2020). Adapun parameter yang dipelajari pada penelitian ini adalah lama ekstraksi, $\mathrm{pH}$ larutan aqueous dan perbandingan volume larutan organic/aquoes (O/A). Dengan metode Taguchi, nilai persentase ekstraksi cobalt pada proses ekstraksi cair - cair pada tiap percobaan akan di analisa untuk menentukan kondisi optimum proses ekstraksi tersebut. Penggunaan metode Taguchi pada ekstraksi cobalt dari slag NPI merupakan sesuatu yang baru yang belum dilakukan pada penelitian penelitian sebelumnya.

\section{BAHAN DAN METODE}

Bahan dan Alat Penelitian

Pada penelitian ini, slag NPI (Peleburan Kupola Balai Penelitian Teknologi Mineral LIPI) sebanyak $5 \mathrm{~kg}$ dilakukan pelindian dengan menggunakan Asam Asetat (Bratachem, Indonesia) 2M sebanyak 12, $5 \mathrm{~L}$ dan Pengatur $\mathrm{pH}$ dengan $\mathrm{NaOH}$ (Bratachem, Indonesia)

Proses ekstraksi menggunakan larutan organik kerosene (Pertamina, Indonesia), Versatic Acid (Merck, German) dan Cyanex 272 (Merck, German). Proses ekstraksi dilakukan menggunakan labu ekstraksi atau corong pemisah seperti ditunjukan pada Gambar 1. 


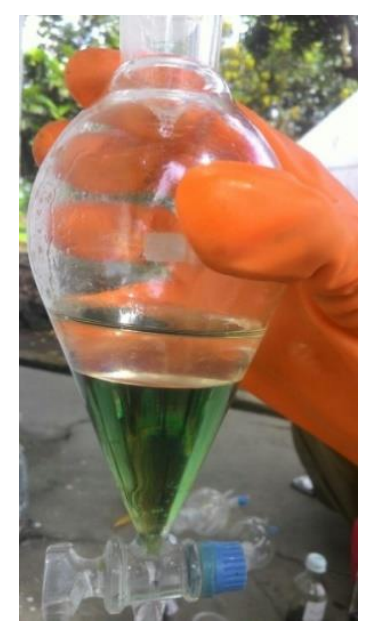

Gambar 1. Larutan organik dan aqueous pada corong pemisah

Metode

Slag NPI dihaluskan menggunakan ball mill kemudian diayak dengan ayakan mesh 50. Serbuk slag NPI setelah diayak kemudian masuk ke proses pelindian yang dilaksanakan selama 24 jam dan diaduk dengan menggunakan stirrer dengan kecepatan $750 \mathrm{rpm}$. Kemudian larutan hasil pelindian dipisahkan dengan endapannya, kemudian diatur pH-nya menggunakan $\mathrm{NaOH}$ (Bratachem, Indonesia) sesuai dengan variasi yaitu pada $\mathrm{pH} 3,5$ dan 6. $\mathrm{pH}$ larutan pada proses pelindian ialah 3. sebelum dilakukan pengaturan $\mathrm{pH}$ dengan penambahan $\mathrm{NaOH}$ Tabel 1. Larutan hasil pelindian kemudian dianalisa menggunakan XRF (Panalytical Epsilon 4 Benchtop XRF, Belanda) untuk mengetahui komposisi yang terdapat didalamnya. Percobaan ini memiliki tiga parameter yaitu waktu operasi, $\mathrm{pH}$ dan nisbah volume pada ekstraksi tahap pertama dengan menggunakan solven Versatic Acid yang dioptimasi menggunakan desain eksperimen Taguchi seperti pada Tabel 1. Parameter parameter yang terbaik hasil optimasi Taguchi di uji cobakan pada ekstraksi cair-cair tahap pertama, kemudian hasilnya digunakan pada ektraksi cair-cair (ekstraksi pelarut) tahap kedua dengan solven Cyanex 272.

Persen Dispersi (\%) ialah persen rasio distribusi yang sesuai dengan Hukum Distribusi Nernst dimana zat terlarut akan mendistribusikan dirinya diantara dua pelarut sehingga akan mencapai kesetimbangan (Treybal, 2013). Rasio konsentrasi zat terlarut dalam dua fasa pada waktu tertentu akan konstan, asalkan zat terlarut tidak terlibat dalam interaksi kimia dalam kedua fasa. Untuk zat terlarut seperti itu, didapatkan persamaan mengenai persen Dispersi ( $\%$ D) yaitu sebagai berikut :

$\%$ Dispersi Kobalt $(D)=\frac{D}{D+V_{\text {aq }} / V_{\text {org }}}$

Dimana $\mathrm{V}$ menunjukkan volume pelarut yang nilainya tetap sesuai dengan perbandingan nisbah volume antara organik dan aqueous. 
Tabel 1. Desain Percobaan Cair-Cair Tahap Pertama menggunakan Versatic Acid

\begin{tabular}{cccc}
\hline Run & pH & $\begin{array}{c}\text { Nisbah Volume } \\
\text { (Organik : Aqueous) }\end{array}$ & Waktu \\
\hline 1 & 3 & $1: 4$ & 10 \\
2 & 3 & $1: 2$ & 20 \\
3 & 3 & $3: 4$ & 40 \\
4 & 5 & $1: 4$ & 20 \\
5 & 5 & $1: 2$ & 40 \\
6 & 5 & $3: 4$ & 10 \\
7 & 6 & $1: 4$ & 40 \\
8 & 6 & $1: 2$ & 10 \\
9 & 6 & $3: 4$ & 20 \\
\hline
\end{tabular}

Ekstraksi cair disebut dengan ekstraksi pelarut, adalah pemisahan konstituen dari larutan cair melalui kontak dengan cairan tidak larut lainnya. Jika zat yang merupakan larutan asalnya mendistribusikan diri secara berbeda antara dua fase cairan, tingkat pemisahan tertentu akan terjadi (Treybal, 2013). Pada persamaan ekstraksi ialah derajat ekstraksi dimana perbandingan antara Co di organik dan di aqueous. Persen ekstraksi dapat dicari dengan :

$\%$ Ekstraksi Kobalt $=\frac{\text { massa } \operatorname{Co}(p p m)}{\text { massa Co awal }(p p m)} \cdot 100 \%$

\section{HASIL DAN PEMBAHASAN}

Slag NPI yang sudah dihaluskan dan diayak menggunakan mesh 50, kemudian dilarutkan dalam larutan asam asetat selama 24 jam. Hasil proses pelindian ini ditunjukan pada Tabel 2. Pada $€$ Tabel ini, kadar nikel dan kobalt sebesar 0,192\% dan 0,386\%. Setelah di endapkan dan disaring, larutan hasil pelindian kemudian diatur $\mathrm{pH}$-nya menggunakan $\mathrm{NaOH}$. Larutan yang sudah diatur pH-nya kemudian diekstraksi menggunakan campuran minyak tanah dan versatic acid. Hasil dari proses ekstraksi tahap pertama ini ditunjukan pada Tabel 3.

Tabel 2. Komposisi larutan pelindian menggunakan XRF

\begin{tabular}{cccccl}
\hline Compound & \multicolumn{2}{c}{ Conc } & Compound & \multicolumn{2}{c}{ Conc } \\
\hline $\mathrm{Mg}$ & 0,423 & $\%$ & $\mathrm{Ni}$ & 0,386 & $\%$ \\
$\mathrm{Al}$ & 0,276 & $\%$ & $\mathrm{Cu}$ & 94,9 & $\mathrm{ppm}$ \\
$\mathrm{S}$ & 0,175 & $\%$ & $\mathrm{Zn}$ & 564,4 & $\mathrm{ppm}$ \\
$\mathrm{Ki}$ & 0,221 & $\%$ & $\mathrm{Rb}$ & 69,7 & $\mathrm{ppm}$ \\
$\mathrm{Ca}$ & 40,868 & $\%$ & $\mathrm{Sr}$ & 689,9 & $\mathrm{ppm}$ \\
$\mathrm{V}$ & 72,6 & $\mathrm{ppm}$ & $\mathrm{Y}$ & 74,7 & $\mathrm{Ppm}$ \\
$\mathrm{Cr}$ & 719,7 & $\mathrm{ppm}$ & $\mathrm{Zr}$ & 8,5 & $\mathrm{Ppm}$ \\
$\mathrm{Mn}$ & 8,027 & $\%$ & $\mathrm{Te}$ & 110,2 & $\mathrm{Ppm}$ \\
$\mathrm{Fe}$ & 49,082 & $\%$ & $\mathrm{La}$ & 294,4 & $\mathrm{Ppm}$ \\
$\mathrm{Co}$ & 0,192 & $\%$ & & & \\
\hline
\end{tabular}


Tabel 3. Persen ekstraksi kobalt dari ekstraksi tahap pertama

\begin{tabular}{ccc}
\hline Run & \% Dispersi Kobalt & \%Ekstraksi Kobalt \\
\hline 1 & 0,0299 & 0,00011 \\
2 & 0,0657 & 0,0038 \\
3 & 0,0013 & 0,0032 \\
4 & 27,6884 & 60,4996 \\
5 & 66,7775 & 50,1248 \\
6 & 65,3174 & 58,5487 \\
7 & 31,8480 & 65,1474 \\
8 & 57,9552 & 73,3818 \\
9 & 73,6086 & 78,8083 \\
\hline
\end{tabular}

Hasil penelitian ini dianalisis dengan Means pada metode Taguchi yang ditunjukan pada Tabel 4. Dari tabel tersebut menunjukkan bahwa nilai delta tertinggi adalah parameter $\mathrm{pH}$, oleh karena itu parameter ini adalah peringkat pertama dari parameter yang mempengaruhi jumlah persentase ekstraksi. Peringkat kedua dan ketiga adalah waktu operasi dan nisbah volume.

Tabel 4. Hasil Analisis SN Rasio Larger is Better

\begin{tabular}{cccc}
\hline Level & $\mathrm{pH}$ & Org/Aq & Waktu Ekstraksi (menit) \\
\hline 1 & 0,0113 & 20,613 & 32,4791 \\
2 & 44,8966 & 15,8825 & 51,5973 \\
3 & 46,5408 & 54,9533 & 7,3724 \\
Delta & 46,5295 & 39,0708 & 44,2249 \\
Rank & 1 & 3 & 2 \\
\hline
\end{tabular}

\section{Pengaruh pH}

Pada penelitian ini, variasi $\mathrm{pH}$ yaitu 3,5 dan 6. Tujuan adanya variasi $\mathrm{pH}$ ini adalah untuk mengendapkan logam-logam yang tidak diinginkan agar mempermudah pengambilan logam kobalt. Logam kobalt $\left(\mathrm{Co}^{3+}\right)$, titanium $\left(\mathrm{Ti}^{4+}\right)$ dan besi $\left(\mathrm{Fe}^{3+}\right)$ akan mengendap pada $\mathrm{pH} 2,5$. Sedangkan logam alumunium $\left(\mathrm{Al}^{3+}\right)$ akan mengendap pada $\mathrm{pH} 4,2$ serta logam berilium $\left(\mathrm{Be}^{2+}\right)$ dan kromium $\left(\mathrm{Cr}^{3+}\right)$ akan mengendap pada $\mathrm{pH} 5,5$ (Nikam and Mohite, 2012). Gambar 1 menunjukan pengaruh $\mathrm{pH}$ terhadap means of percentage extraction bahwa kenaikan ekstraksi kobalt tertinggi diperoleh saat $\mathrm{pH}$ 6. Hal ini menunjukkan bahwa $\mathrm{pH} 6$ adalah $\mathrm{pH}$ paling sesuai untuk menarik ion kobalt pada larutan aquoeous kedalam larutan organik dengan menggunakan Versatic Acid. Sedangkan pada $\mathrm{pH}$ rendah yaitu $\mathrm{pH}$ 1-3 tidak terjadi ekstraksi kobalt ke larutan organik dikarenakan kobalt akan tetap berada pada fasa aqueous sedangkan ion nikel yang akan masuk ke fase oganik. Pada $\mathrm{pH}$ yg rendah pula, banyak pengotor seperti ion besi dan mangan yang masih banyak berada pada larutan aqueous (Sole, 2008). Penggunaan Versatic Acid pada larutan organik juga akan menghalangi masuknya ion kalsium kedalam larutan organik (Nikam and Mohite, 2012). 


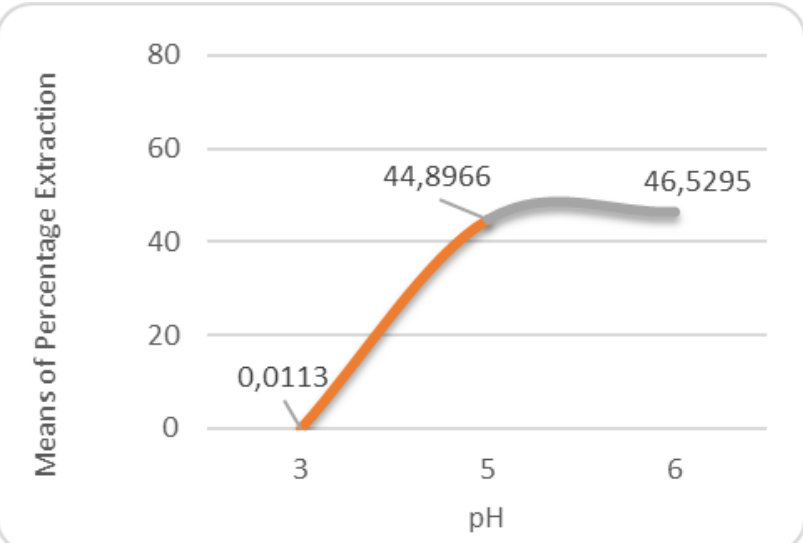

Gambar 1. Pengaruh $\mathrm{pH}$ terhadap means of percentage extraction

\section{Pengaruh Waktu}

Pada penelitian ini, variasi waktu operasi adalah 10, 20 dan 40 menit. Pengaruh waktu operasi terhadap means of percentage extraction dapat dilihat pada gambar 2 yang menunjukkan bahwa waktu operasi terbaik adalah 20 menit. Ekstraksi Co pada durasi 20 menit lebih besar dari durasi 10 menit. Kenaikan ini menunjukan semakin lama waktu proses yang digunakan maka akan semakin tinggi nilai persen ekstraksi yang diperoleh. Hal ini disebabkan semakin lama waktu proses solvent extraction menandakan bahwa fasa organik memiliki waktu yang semakin lama untuk mengikat logam Co dan berpindah ke fasa organik, sehingga semakin banyak logam kobalt yang dapat terikat dan berpindah fasa. Co pada larutan organik mengalami penurunan pada waktu 40 menit. Penurunan kadar Co terjadi bila pengadukan yang terlalu lama pada proses ekstraksi. Hal ini disebabkan karena fasa aqueous telah banyak pelepasan ion hidrogen sehingga ada kemungkinan asam dari fasa organik mengikat kembali ion hydrogen yang terlepas di fasa aqueous sehingga terjadi reaksi reversible (Sole, 2008; Sudibyo et al., 2018).

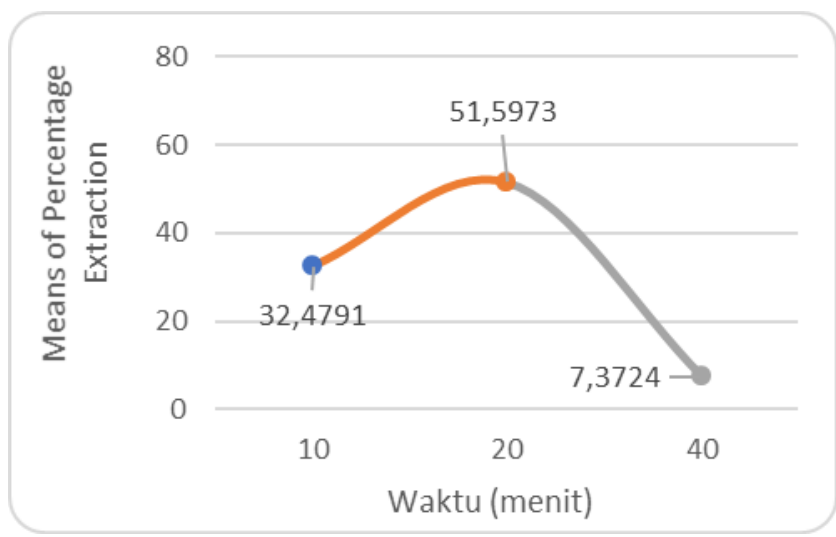

Gambar 2. Pengaruh Waktu terhadap persentase kenaikan ektraksi kobalt

\section{Pengaruh Nisbah Volume}

Pada penelitian ini, variasi nisbah volume (O/A) adalah 0,$25 ; 0,50$ dan 0,75 . Hasil analisa Taguchi menggunakan Metode Means menunjukan bahwa nilai optimum didapat pada nisbah volume (organik/aqueous) 0,75 . Sedangkan pada proses yang menggunakan nisbah volume (organik/aqueous) yang lebih kecil dari 0,75 akan mengalami penurunan. Fenomena ini terjadi karena larutan organik yang mengandung Versatic Acid akan menghalangi masuknya kalsium dan akan mengambil cobalt dan nikel. Semakin banyak logam nikel dan kobalt terekstraksi maka akan semakin banyak kalsium yang terlepas sehingga semakin bertambah jumlah 
kalsium dalam aqueous. Pengaruh nisbah volume O/A dilihat pada Gambar 3 grafik hasil percobaan dengan parameter nisbah volume O/A terhadap faktor kenaikan Ca. Semakin tinggi nilai nisbah volume O/A semakin tinggi persen ekstraksi Ni sehingga diperoleh faktor kenaikan Ca yang semakin tinggi, hal ini disebabkan oleh semakin banyak jumlah kalsium yang terlepas dari ikatan nikel sehingga jumlah kalsium dalam fasa aqueous semakin bertambah (Sole, 2008; Sudibyo et al., 2018).

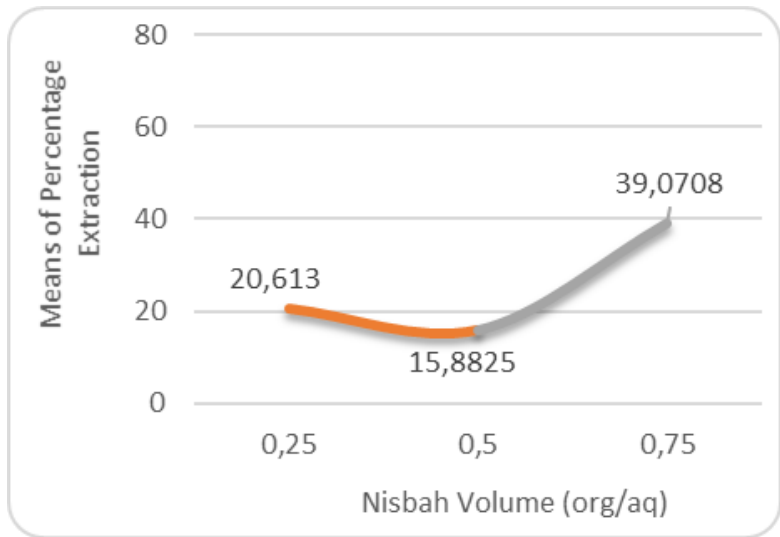

Gambar 3. Pengaruh nisbah volume terhadap persentase kenaikan ekstraksi kobalt

\section{Hasil Percobaan Ekstraksi Cair-Cair Pada Kondisi Optimum}

Kondisi optimum yang didapatkan menggunakan metode Taguchi didapatkan dari Tabel 4, dengan nilai SN Ratio tertinggi didapatkan $\mathrm{pH}$ pada nilai 6 , nisbah volume (O/A) pada nilai 0,75 dan waktu pada 20 menit operasi. Pada kondisi optimum didapatkan ekstraksi Cobalt sebanyak 19,0517 ppm.

\section{KESIMPULAN}

Pengaruh metode Solvent Extraction pada proses pemisahan kobalt dari slag NPI skala laboratorium. Parameter $\mathrm{pH}$ larutan, waktu operasi dan nisbah volume yang diteliti memiliki pengaruh yang signifikan terhadap persentase ektraksi kobalt. Kondisi terbaik untuk proses solvent extraction diperoleh pada $\mathrm{pH} 6$, nisbah volume (O/A) 0,75 dan waktu operasi 20 menit dengan menggunakan analisis Taguchi.

\section{Daftar Pustaka}

Amin, M. et al. (2019) 'Process of andesite stone as the material of cement substitution in making paving block', IOP Conference Series: Materials Science and Engineering, 478(1). DOI: $10.1088 / 1757-899 X / 478 / 1 / 012040$.

Astuti, W. et al. (2016) 'Comparison of the effectiveness of citric acid and other acids in leaching of low-grade Indonesian saprolitic ores', Minerals Engineering. Elsevier Ltd, 85(December), pp. 1-16. DOI: 10.1016/j.mineng.2015.10.001.

De-qing, Z. H. U. et al. (2012) 'Mineralogy and crystal chemistry of a low-grade nickel laterite ore', 22. DOI: 10.1016/S1003-6326(11)61264-8.

Du Preez, A. C., and Preston, J. S. (2004) 'Separation of nickel and cobalt from calcium, magnesium, and manganese by solvent extraction with synergistic mixtures of carboxylic acids', Journal of The South African Institute of Mining and Metallurgy, 104(6), pp. 333-338.

Nikam, G. H., and Mohite, B. S. (2012) 'Liquid-Liquid Extraction and Separation of Cobalt (II) from Sodium Acetate media using Cyanex 272, 2(1), pp. 75-82.

Park, K. H., and Mohapatra, D. (2006) 'Process for cobalt separation and recovery in the presence of nickel from sulfate solutions by Cyanex 272, Metals and Materials 
International, 12(5), pp. 441-446. DOI: 10.1007/BF03027712.

Sole, K. C. (2008) 'Solvent extraction in the hydrometallurgical processing and purification of metals: Process design and selected applications', Solvent Extraction and Liquid Membranes: Fundamentals and Applications in New Materials, (January 2008), pp. 141-200. DOI: 10.1201/9781420014112.

Sudibyo et al. (2020) 'Application of artificial neural network model to predict limiting current for cobalt magneto-electrodeposition', Proceedings of The 3RD International Seminar on Metallurgy and Materials (ISMM2019): Exploring New Innovation in Metallurgy and Materials, 2232(April), p. 020009. DOI: 10.1063/5.0001932.

Sudibyo, S. et al. (2018) 'Solvent Extraction Process for the Recovery Cobalt and Nickel From Low-Grade Laterite Using Batch Recycle System', Widyariset, 4(2), p. 189. DOI: 10.14203/widyariset.4.2.2018.189-196.

Treybal, R. E. (2013) Scilab Textbook Companion for Mass - Transfer Operations Book Description. 